\title{
SUBSGRIPTION INFORMATION
}

\section{$\square$ YES! I want to continue my free subscription to CNS SPECTRUMS}

Name:

Address:

E-mail:

Specialty:
FAX: 212.674.2891

MAIL:

CNS SPECTRUMS

MBL Communications

665 Broadway, Suite 805

New York, NY 10012-2302

\section{PAID SUBSCRIPTIONS}

$\square$ PRIMARY PSYCHIATRY

\section{First in Applied Psychiatric Medicine}

12 issues per year. One-year subscription rate: Domestic: $\$ 90$; Foreign: \$145; In-training: \$50 (1999)

\section{TEN}

\section{The Economics of Neuroscience}

12 issues per year. One-year subscription rate: Domestic: $\$ 120$; Foreign: $\$ 185$; In-training: $\$ 75$

\section{ONE}

\section{Oncology Economics}

12 issues per year. One-year subscription rate: Domestic: $\$ 120$; Foreign: $\$ 185$; In-training: $\$ 75$

\section{Billing}

Invoice Me

Visa $\square \mathrm{MC} \square \mathrm{AmEx}$

Name:

Card \#:

Exp. Date:

\section{Gontinuing Medical education}

Category 1 credits for psychiatrists, primary care physicians, and neurologists are available each month in both Primary Psychiatry and CNS Spectrums, as well as on MBL's Web site:

\section{www.medicalbroadcast.com}

To participate, complete and mail the test and registration forms that are included in every issue of

Primary Psychiatry and CNS Spectrums, or visit our Web site. 


\section{Introduction}

CNS Spectrums is a peer-reviewed journal that publishes original scientific literature and reviews on a wide variety of neuroscientific topics of interest to the clinician. CNS Spectrums publishes 12 issues in 2000. As the immense prevalence of comorbid diseases among patients seen by psychiatrists and neurologists increases, these physicians will jointly diagnose and treat the neuropsychiatrically ill. Our mission is to provide these physicians with an editorial package that will enhance and increase their understanding of neuropsychiatry; therefore, manuscripts that address crossover issues germane to neurology and psychiatry will be given immediate priority.

\section{Scope of Manuscripts}

CNS Spectrums will consider the following types of articles for publication:

Original Reports: Original reports present methodologically sound original data.

Reviews: Reviews are overview articles that summarize and synthesize the literature on various topics in a scholarly and clinically relevant fashion. Suitable topics include mood disorders, schizophrenia and related disorders, personality disorders, substance-use disorders, anxiety disorders, neuroscience, psychosocial aspects of psychiatry, child psychiatry, geriatric psychiatry, and other topics of interest to clinicians. nb: Original flowcharts designed to aid the clinician in diagnosis and treatment will be considered for publication in reviews and are encouraged.

Case Reports: Single or multiple case reports will be considered for publication.

Letters to the Edltor: Letters will be considered for publication.

\section{Manuscript Submissions}

General informatlon: Four copies of the manuscript should be submitted to Eric Hollander, editor (or in Europe to Joseph Zohar, international editor), c/o MBL Communications, Inc., 665 Broadway, Suite 805, New York, NY 10012; T: 212.328.0800, F: 212.328.0600. Authors are required to submit their manuscripts on computer disks. If possible, please provide them in MSWord, WordPerfect, or Word for Windows in either a Macintosh or IBM format. (Saving the file in a lower version, eg, MSWord 3.0, is also encouraged.) Disks should be labeled with the word-processing program, title of paper, and first author's name.

Letters of permlssion to reproduce previously published materlal: All material reproduced from previously published copyrighted material must be accompanied by a letter of permission from the copyright holder. All such material should include a full credit line (eg, in the figure or table legend) acknowledging the original source. Any citation of unpublished material or personal communication should also be accompanied by a letter of permission for anyone who is not an author of the paper.

Peer review: Authors should provide five names of particularly qualified potential reviewers with no conflict of interest in reviewing the work. Contact information, including complete address, phone, fax numbers, e-mail address, and affiliations, should be included. The corresponding author will be notified by the editors when a decision regarding acceptance has been made. Accepted manuscripts and letters will be edited for clarity and style.

\section{Manuscript Preparation}

Length: Reviews should not exceed 20 manuscript pages $(10,000$ words). Original reports should not exceed 15-25 manuscript pages (6,250 words, maximum). Letters should not exceed 2-6 manuscript pages (1,500 words, maximum). Single case reports should not exceed 10-15 manuscript pages (3,750 words, maximum) and may be submitted with a photograph, if applicable. Diagnostic/treatment algorithms (see Reviews) should contain an extensive introduction, a flowchart or series of graphs that fill eight to 12 journal pages, and a concise summary.

Spacing: One space should be left after commas and periods. Manuscripts should also be double-spaced.

Abstract: Authors should provide a brief abstract.

References: American Medical Association style. See the following examples:

1. Jones J. Necrotizing Candida esophagitis. JAMA. 1980;244:2190-2191.

2. Stryer L. Biochemistry. 2nd ed. San Francisco, Calif: WH Freeman Co; 1980:559-596.

Copyright: Materials are accepted for exclusive publication in CNS Spectrums and become the property of CNS Spectrums. Permission to reproduce material must be obtained from the publisher.

\section{Disclosure of Commercial Interests}

The authors must include a statement about all forms of support, including grant and drug company support. Such information may, at the editor's discretion, be shared with reviewers. If the article is accepted for publication, the editors will consult with the authors as to whether this information should be included in the published paper.

Reprints: Authors of reviews and original materials published in CNS Spectrums may order reprints of their articles directly from the publisher, James La Rossa Jr., MBL Communications, Inc., New York, NY 10012; T:212.328.0800, F: 212.328.0600.

Continuing Medical Education requirements: Authors must submit two multiple-choice questions with answers.

\section{Submission Checklist}

1. Original manuscript plus copies

2. Copies of permission letters to reproduce previously published and unpublished material

3. A brief abstract of article.

4. Two multiple-choice questions with answers

5. Disk labeled with the word-processing program, title of paper, and first author's name

6. Names and addresses of five potential reviewers. 


\section{GuIDE TO DSM-IV ANd ICD-10 CODES}

Dementia of the Alzheimer Type, With Early Onset With Depressed Mood

DSM-IV

ICD-10

Specify if: With Behavioral Disturbance

290.13

F00.03

Specify if: With Behavioral Disturbance

Delirium Due to: Indicate General Medical Condition

Psychotic Disorder Due to: Indicate General Medical Condition With Delusions

With Hallucinations

Mood Disorder Due to: Indicate General Medical Condition

Anxiety Disorder Due to: Indicate General Medical Condition

Amnestic Disorder Due to: Indicate General Medical Condition

Dementia NOS

Amnestic Disorder NOS

Schizophrenia

Schizophrenia-Disorganized Type

Schizophrenia-Catatonic Type

Schizophrenia-maranoid Type

Schizophrenia-Residual Type

Schizoaffective Disorder

Schizophrenia-Undifferentiated Type

Major Depressive Disorder

Bipolar I Disorder

Bipolar Disorder NOS

Bipolar II Disorder

Mood Disorder NOS

Psychotic Disorder NOS

Autistic Disorder

Asperger's Disorder

Pervasive Developmental Disorder NOS

Anxiety Disorder NOS

Panic Disorder Without Agoraphobia

Generalized Anxiety Disorder

Dissociative Identity Disorder

Dissociative Disorder NOS

Factitious Disorder NOS

Panic Disorder With Agoraphobia

Agoraphobia Without History of Panic Disorder

Social Phobia

Specific Phobia

Obsessive-Compulsive Disorder

Dysthymic Disorder

Depersonalization Disorder

Body Dysmorphic Disorder

Somatization Disorde

Somatoform Disorder NOS

Cyclothymic Disorder

Alcohol Dependence

Cocaine Dependence

Cannabis Dependence

Amphetamine Dependence

Alcohol Abuse

Cannabis Abuse

Cocaine Abuse

Amphetamine Abuse

Stuttering

Anorexia Nervosa

Tic Disorder NOS

Tourette Disorder

Primary Insomnia

Primary Hypersomnia

Sleepwalking Disorder

Dyssomnia NOS

Nightmare Disorder

Parasomnia NOS

Eating Disorder NOS

Bulimia Nervosa

Feeding Disorders of Infancy or Early Childhood

Communication Disorder NOS

Posttraumatic Stress Disorder

Depressive Disorder NOS

Impulse-Control Disorder NOS

Pathological Gambling

Pyromania

Kleptomania

Trichotillomania

Disruptive Behavior Disorder NOS

Attention-Deficit/Hyperactivity Disorder, Combined Type

Attention-Deficit/Hyperactivity Disorder NOS

Learning Disorder NOS

Developmental Coordination Disorde

Narcolepsy

Sleep Disorder Due to: Indicate General Medical Condition

Delirium NOS

290.2

293.0

293.81

293.82

293.83

294.0

294.8

295

295.10

295.20

295.30

295.60

295.70

295.90

296

296

296.80

296.89

296.90

298.9

299.00

299.80

299.80

300.00

300.01

300.02

300.14

300.15

300.19

300.21

300.22

300.29

300.3

300.4

300.6

300.7

300.81

300.81

301.13

303.90

304.20

304.30

304.40

305.00

305.20

305.60

305.70

307.0

307.1

307.20

307.23

307.42

307.44

307.46

307.47

307.47

307.47

307.50

307.51

307.59

307.9

309.81

311

312.30

312.31

312.33

312.34

312.39

312.9

314.01

314.9

315.9

315.4

347

780.09

F00.13

F05.0

F06.2

F06.0

F06

F06.4

FO2.8

$\mathrm{FO} 3$

R41.3

F2O

F20.1

F20.2

F20.0

F20.5

F25

F20.3

F32

F30

F39

F31.8

F39

F29

F84

F84.5

F84.9

F41

F41.1

F44.81

F44. 9

F68.1

F40.01

F40

300.23 F40.1

F 40.2

F42.8

F34.1

F48.1

F45.2

F45.

F45.9

F34

F10.2

F14.2

F12.2

F15.2

F10.1

F12.1

F14.1

F15.1

F98.5

F50

F95.2

F51.0

F51.1

F51.3

F51.9

F51.5

F51.8

F50.9

F50.2

F98.2

F80.9

F43.1

F32.9

F63.9

F63.0

F63.1

F63.2

F63.3

F91.9

F90

F90.9

F81.9

F82

F82

G47

F05.9 
Name:

Address:

\section{E-mail:}

\section{Specialty:}

Your comments are important to us. This easy-to-use form provides you with the opportunity to express your opinions. Our goal is to make CNS Spectrums your source for practical and clinical neuropsychiatric information. By filling out this FaxBack form, you will enable us to incorporate your views about our editorial content in future issues. Please fill out this form in its entirety. Thank you.

1. On a scale of 1 to 5 ( $1=$ Poor, $5=$ Excellent), please indicate your level of interest and/or satisfaction with the editorial content in this issue.

\section{Cover Story}

$\begin{array}{lllll}1 & 2 & 3 & 4 & 5\end{array}$

\section{Departments}

CNS News

$\begin{array}{lllll}1 & 2 & 3 & 4 & 5 \\ \mathrm{CME} & & & \\ 1 & 2 & 3 & 4 & 5\end{array}$

$\begin{array}{lllll}1 & 2 & 3 & 4 & 5\end{array}$

2. Which areas of neuropsychiatry would you like us to cover in the future?
3. Please describe your reading pattern for this issue:
O cover to cover
skim Table of Contents
$O$ select items of interest
O skim text
$\mathrm{O}$ did not read

FAX: 212.674.2891

MAIL:

CNS SPECTRUMS

MBL Communications

665 Broadway, Suite 805

New York, NY 10012-2302
4. On a scale of 1 to 5 ( $1=$ Incomplete, $5=$ Comprehensive), how would you describe the depth of coverage for this issue?

$$
\begin{array}{lllll}
1 & 2 & 3 & 4 & 5
\end{array}
$$

\section{Any other comments?}

\section{Please indicate your title: \\ psychiatrist \\ neurologist}

When you send us this form, you'll receive one complimentary slide library and one complimentary reference material. Please make your selection below.

\section{SLIDE LIBRARIES}

Current Uses of Dopamine Agonists

Monotherapeutic Uses for Dopamine Agonists

Management of Social Anxiety Disorder (Social Phobia)

$\square$ Current Treatments in Alzheimer Disease

The Economic and Emotional Impact of Social Anxiety Disorder

$\square$ Diagnosis and Treatment of Premenstrual Dysphoric Disorder
The Use of Anticonvulsants in the Treatment of Neuropathic Pain

$\square$ Overview of Social Anxiety Disorder (Social Phobia): Recognition and Treatment

$\square$ Current Treatment for Restless Legs Syndrome

\section{Reference Materials}

The Black Book of Psychotropic Dosing and Monitoring 2000

1999 Guide to Psychotropic Drug Interactions 
LUVOX Brief Summary (For full Prescribing Information and Patient Information, refer to package insert.)

INDICATIONS AND USAGE

LWVX Tablets are indicated for the treatment of obsessions ond compulsions in odults ond children ond adolescents (cges 8-17) with Obsessive Compulsive CONTRAINDICATIONS

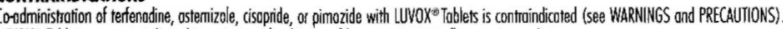

LUVOX" Toblets ore contraindicated in pctients with a history of hypersensitivity to fuvoxomine maleote.

WARNINGS

In patients receiving onother serotonin reuptake inhibitor drug in combination with monoamine oxidase inhibitiors (MAO) there have been reports of serious, sometimes fatal, reactions. Some cases presented with fectures resembling neuroleptic molignont syndrome. Therefore, it is recommended that LVYOX Tablets not be used in combinotion with o MAOl, or within
14 days of discontinuing treatment with a MAOI. After stopping LUVOX Tablets, af least 2 weeks should be allowed belore starting a $\mathrm{MAOI}$.

Terfenodine, astemizole, cisapride, and pimozide are all metabolized by the cytochrome P450Illa4 isozyme. Increased plasme concentrations of terfenodine, astemizole, cisopride, and pimozide cause aT prolongation and have been ossociated with torsades de pointes-type ventricular tachycardia, sometimes fatal. Although it has not been definitively demonstrated that
fluvoxamine is a potent IllA4 inhibitor, it is likely to be. Consequently, it is reconmended that fluvoxamine not be used in combination with either tertenadine, astemizole, cisapride, and pimozide.

Other Pofentially Important Drug Interactions. (Also see PRECAUTiONS - Diug Interoctions) Benzodiazepines: Benzodiozepines metabolize by hepotic oxidation (e.g., olprozolom, nidozolom, trizzolam, etc.) should be used with caution beccusse the clearance of these drugs is likety to be reduced by fluvoxomine. The cleoronce of benzodiazepines metobolized by glucuronidotion (e.g., lorozepom, oxozepom, temozepom) is unlikely to be offected by fluvoxamine. Alprazolam: When fluvoxamine malease (100 $\mathrm{mg}$ gd) ond alprozolom (1 $\mathrm{mg}$ gid) were condministered to steody state, plasmo concentrations ond other phormecokinetic parcometers $\left(A \cup C, C_{m a x}, T_{b}\right)$ of olprozolam were opproximately twice those observed when olprozolom wos odministered alone; oral clearonce wos reduced by obout $50 \%$. The elevoted plasma olprazolam concentrotions resulted in decreased psychomotor performonce ond memory. This interaction, which hos not been investiocted using higher doses of fluvoxomine, moy be more pronounced if a $300 \mathrm{mg}$ doily dose is co-odministered, porticuiady since fluvoxomine exhibits nontineor phormocokinetics oves the cosoge ronge $100-300 \mathrm{mg}$. If alprazolom is $0^{-}$

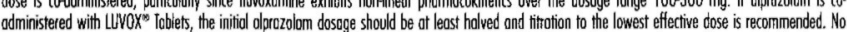

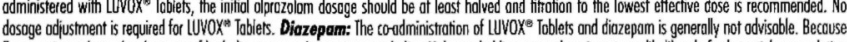
dosage odjustment is required for LUVOX Tabiets. Diazepam: The condministrofion of LUVOX Toblets ond diazepam is generally not odvisoble. Beccuse

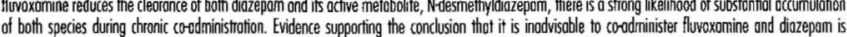
of both species during chronic co-doministration. Evidence supporting the conclusion thot it is inodvisable to co-ddminister fluvoxomine and diazepam is
derived from o study in which heolthy volunteers taking $150 \mathrm{mg} /$ doy of fluvoxomine were odministered a single oral dose of $10 \mathrm{mg}$ of diozepom. In these

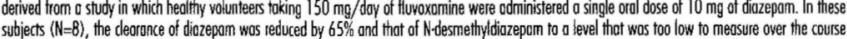

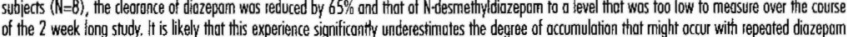
of the 2 week long study. It is likely that this experience significanty underessimotes the degrae of occumulation that might occur with repented dinzepen administration. Moreover, os noted with alprazolam, the effect of tivoxomine may even be more pronounced when if is odministered of higher doses. Accordingly, diozepam and fluvoximine should not ordinacily be co-ndministered. Theophylline: The effect of steadystate fluvoxamine $(50 \mathrm{mg}$ bid) on the phormacokinetics of o single dose of theophylline (375 mg os $442 \mathrm{mg}$ aminophylline) wos evoluoted in 12 hedlithy nonsmoking, male volunteers. The clearonce of theophyline wos decreased approximotely threet-old. Therefore, if theophyline is co-administered with fuvoxamine moleote, its dose snould be reduced to one third of the usuol daily mointenance dose ond plosmo concentrotions of theophylline should be monitored. No dosoge odjustment is

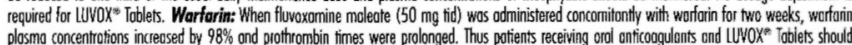

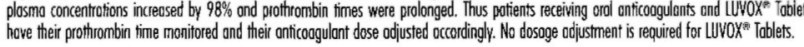
PRECAUTIONS

\section{General}

Activation of Mania/Hypomania: During premorketing sudies involving primarily cepressed patients, hypomanic or monic occurred in opproximate $1 \%$ of potients treated with fluvoxomine. Activotion of monio/hypomanic hos olso been reported in a small proportion of patients with major offective

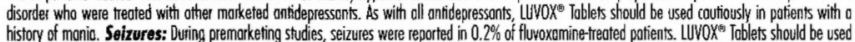

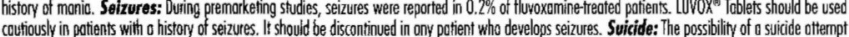
coltiously in patients with o history of seizures. It shoud be discontinued in ony potient who develops seizures. Suicide: The possibility of a sucide ottermpt Close supervision of high nisk potients should accompony initiol drug thercopy. Prescriptions for Luvox Toblets should be wirtten for the smallest quantify of Close supervision of high nisk potients should accompony initiol drug thercopy. Prescriptions tor Luvox Toblets should be written for the smallest quantify of toblets consistent with good patient monogement in order to reduce the risk of overdose. Use in Patients with Concomitont Illness: Closery

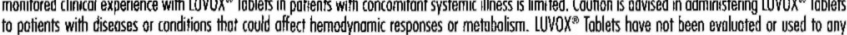

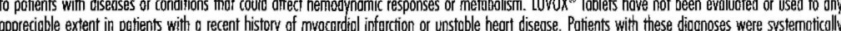
excluded from meny clinical studies during the product's premoriketing testing. Evaluction of the electrocordiogroms for potients with depression or OCD who participoted in premaiketing studies reveoded no differences between fluvoxomine and piocebo in the emergence of clinically importont $E(G$ changes. In potients with liver dysfunction, fivoxoxamine clecronce wos decreosed by approximately $30 \%$. LUVOX Toblets should be slowly fircted in patients with liver dusfunction during the initiotion of treatment.

Informetion for Patients: Physicions are advised to discuss the following issues with patients for whom they prescribe LUVOX® Toblets: Interference with Cognitive or Motor Performance: Since ony psychonctive drug mioy impcir judgement, thinking, or motor skills, potients should be coution obout operoting hazordous mechinery, induding automobiles, until they ore certcin thot LWYOX ${ }^{\circledR}$ Tabiets theropy does not odversely offect their cbility engoge in such activities. Pregnancy: Potients shruld be advised to notify their physicions if they becrme pregnont or intend to become pregnnont during (See PRECAUTIONS - Nussing Mothers.) Consomitont Medication: Patients should be odvised to notify their physicions if they ore toking, or plon to

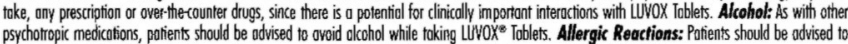
notily their physicions if they develop a rash, hives, or o related allergic phenomenon during theropy with LivoX Tablets.

\section{Toboratory Tests: There ore no speciticlaborotory test recommented.}

Drug Interactions: There hove been rore postmarkefing reports describing potients with weokness, hyperreflexio, cnd incoordination following the use of o selective serotonin reuptake inhibito (SSRl) ond sumotripton. If concomitant treatment with sumotrigton and SSRI (e.G., fluoxetine, fluvoxomine

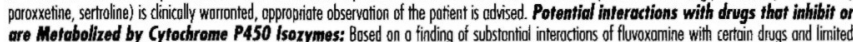
are Mefabolized by Cyrochrome P450 Isozymes: Bosed on o tinding of substontial interoctions of fluvoxomine with certain drugs and limited

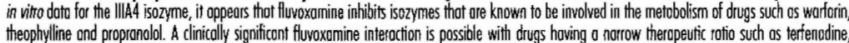
theophylline ond propranolol. A clinicolly significont fluvoxamine interoction is possible with drugs hoving a norrow thercpeutic sotio such os terfendedine, ostemizole, cisopide, or pimozide, worforin, theophylline, certcin benzodiazepines ond phenytoin. If LUVOX $x^{8}$ Toblets are to be administered together with o drug thot is eliminated vio oxidotive metobolism ond hes a norrow therapeutic window, plosmo levels ond/ or pharmacodynomic effects of the latter drug should be monitored closely, ot leost until steodystote conditions are reoched. Pleose see complete prescribing infornation for recommendations regarding CNS drugs such as monoamine oxidosa inhibitors, olprozolom, diozzeam, lorazepom, lithium, tryptophan, dozapine, alcohol, tricycic antidepressonts,

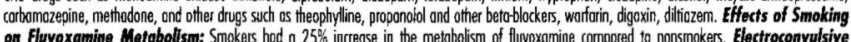

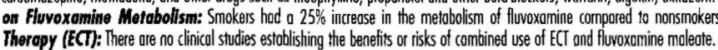

Corcinogenesis, Mutagenesis, Impoirment of Fertility

Carcinogenesis: There is no evidence of corrinogeniciy, mutogenicity or impoirment of fertility with fluvoxamine maleate. There wos ne evidence of

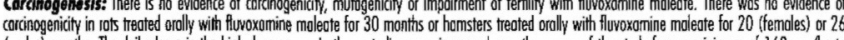
carcinogenicity in rots treated orolly with fluvoxamine moleate tor 30 months or homsters treated orally with fluvoxomine maleate for 20 (females) or 26
(moles) months. The daily doses in the high dose groups in these studies weete increased over the cousse of the study from a minimum of $160 \mathrm{mg} / \mathrm{kg}$ to (moles) months. The daly doses in the high dose groups in these studies weet increased over the course of the study from a minimum of $160 \mathrm{mg} / \mathrm{kg}$ to
o moximum of $240 \mathrm{mg} / \mathrm{kg}$ in rots, ond from a minimum of $135 \mathrm{mg} / \mathrm{kg}$ to o moximum of $240 \mathrm{mg} / \mathrm{kg}$ in hansters. The moximum dose of $240 \mathrm{mg} / \mathrm{kg}$

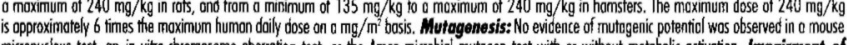
is approximately 6 times the moximum humon dally dose on o $\mathrm{mg} / \mathrm{m}^{2}$ bosis. Mutagenesis: No evicence of mutragenic potentiol wos observed in $\mathrm{mous}$ daily dose on a mg/ $\mathrm{m}^{2}$ basis) had no effect on moting performance, duration of gestation, or pregnonocy rote.

Pregnancy.

Toratogeni Effects: Pregnency Category C: In terotology studies in rots and robbits, daily oral doses of fluvoxomine moleate of up to 80 and $40 \mathrm{mg} / \mathrm{kg}$, respectively (approximately 2 times the moximum humen daily dose on a $\mathrm{mg} / \mathrm{m}^{2}$ basis) caused no fetal malformations. However, in other

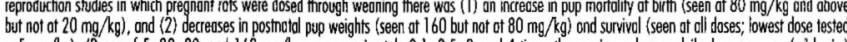
$=5 \mathrm{mg} / \mathrm{kg}$ ). (Doses of $5,20,80$, and $160 \mathrm{mg} / \mathrm{kg}$ ore opproximately $0.1,0.5,2$, and 4 times the maximum human daly dose on a $\mathrm{mg} / \mathrm{m}^{2}$ basis.) While the sesults of a cross fostering study implied that at least some of these results likey occurred secondarily to motemal toxicity, the role of a direct drue effect on the fetetuses or pups could not be ruled out. There are no adequete ond welk-controlled studies in pregnont women. Fluvoxomine meleate should be Donchy only if the potential benefit justifies the potential isk to the fetus.

Labor and Delivery: The effect of fluvoxomine on labor ond delivery in humans is unknown.

Nursing Moshers: As for mony other drugs, fllwoxomine is secreted in human breast milk, The decision of whether to discontinue nursing or to discontinue the drug should toke into account the potential for serious odverse effects from exposure to fluvoxomine in the nursing intent os well as the potential benefis of Luvoxs (fluvoxomine molecte) Tablets theropy to the mother.

Pediatric Use: The efficacy of fluvoxarnine maleate for the treatment of Obsessive Compulsive Disorder was demonstroted in a 10-week multicenter plocebo controlled study with 120 outpotients oges 8-17. The adverse event protile observed in that study wos generally similar to thot observed in adult plocebo controlled study with 120 outpotients oges 8 with fluvoxomine (see ADVERSE REACIIONS).

Decreosed appetite ond weight loss hove been observed in associotion with the use of fluvoxomine as well as other SSRRs. Consequently, regulor monitoning of weight and growith is secommended if treatment of a child with on SSRl is to be continued long term.

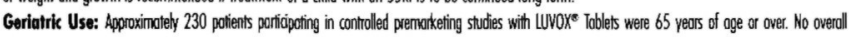

differences in sctey were observed between these patients ond younger patients. Other teported clinical experience hos not idenaffied differences in response between

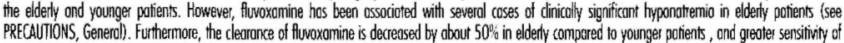

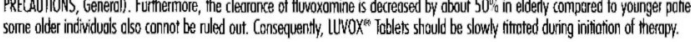

ADVERSE REACTIONS

Associated with Discontinuation of Treatment: Of the 1087 OCD ond depressed patients treated with fluvoxamine mcleate in controlled clinice Associated with Discontinuation of Trealment: Of the 1087 OCD ond depress
triols conducted in North America, $22 \%$ discontinued treatment due to on adverse event.

Incidence in Controlled Triols - Commonly Observed Adverse fvents in Controlled Clinicol Trials: LUvoX* Toblets hove been studied in controlled tials of $O C D(\mathrm{~N}=320)$ and depression $(\mathrm{N}=1350)$. In penerol, odverse event rotes were similior in the two doto sets os well os in the pediatic $0 \mathrm{CD}$ study. The most commonly observed adverse events ossocioted with the use of LUVOX

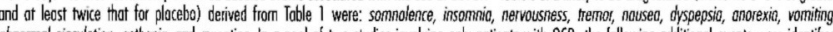
obnormol ejoculation, asthenia, and sweating in o pool of two studies involving only potients with $\mathrm{CC}$, the

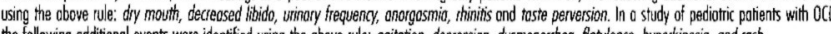
the following odditionol events were identified using the above rule: agitotion, depression, dysnenorrhen, flathlence, hyperkinesia, and rosh.

Adverse Events Occurring at an Incidence of 1\%: Toble l enumerates adverse events thot occured of o frequency of $1 \%$ or move, ond werc more frequent than in the plocebo group, oniong potients treoted with LUVOX" Toblets in two shorrtterm placebo controlled OCD triols (10 week) an depression trials $(6$ week) in which patients were dosed in a range of generally 100 to $300 \mathrm{mg} /$ doy. This toble shaws the percentage of patients in each
group wha hod or leost one occurrence of an evert at some fime during their treorment. Reported odverse events were classified using a standard COSTARTgroup wha hod of least one occurrence of an event at some fime during their treatment. Reparted odverse events were classfied using a stondard COSTART. medical proctice where potient chareccteristics and ather foctors moy differ from those that prevailed in the clinical triols. Similarly, the cited frecuencis cannot be compoeded with figures obtained from other clinical investigations involving different treatments, uses, ond investigators. The cited figures, however, do provide the prescribing physicicn with some bosis for estrmating the relative contribution of drug ond ron-drug foctors to the sideeffect incidence sote in

Table 1: TREATMENT-EMERGENT ADVERSE EVENT INCIDENCE RATES BY BODY SYSTEM IN ADULT OCD AND DEPRESSION POPULATIONS COMBINED' (ffwroxonine [N=892] v5. plocebo [N=778] by potients-pecentage): BODY AS WHOLE: Headoche (22 vs. 20);

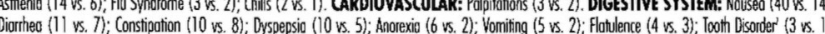
Dysphogio (2 vs. 1). NERVOUS SYSTEM: Somnolence (22 vs. 8); insornio (21 vs. 10); Dry Mhouth (14 vs. 10); Nervousness (12 vs. 5); Dizziness (11)

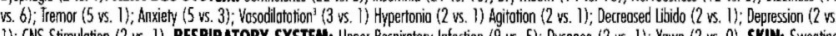
1); (NS Stimulation (2 vs. 1). RESPIRATORY SYSTEM: Upper Respirotory Infection (9 vs. 5); Oysprea (2 vs. 1); Yown (2 vs. 0). SKIN: Swection

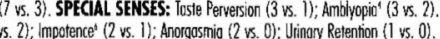

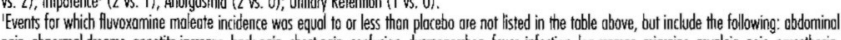

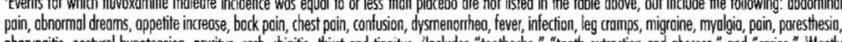

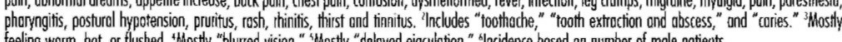
eeling worin, hot, or flushed. "Whostly "blured vision." "Mostly "celoyed ejoculation." "Incidence based an number of mole patients.

Adverse Events in OCD Placebo Controlled Studies Which are Markedly Different (defined as at loost o fwo-fold difference) in Rote from the Pooled Event Rotes in OCD and Depression Placebo Controlled Studies: The events in OCD studies with 0 wo.fol

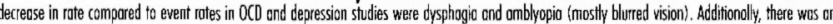
approximate $25 \%$ decrease in nousea. The events in OCD studies with a fwo-fold increase in rote compored to event rotes in OCD ond depression studies

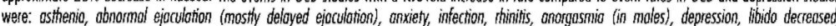

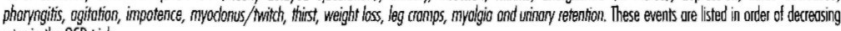
rotes in the $\mathrm{OCD}$ triols

Other Adverse Events in OCD Pediatric Population: In Pediotic patients (N=57) treated with LVVOX" Tablets, the overall profile of adverse events is similar to thot seen in adilt studies. Other reactions which have been reparted in two or more pediatic poitents, and were more frequent than in the plocebo group group were: obnom

Wight decreasse.

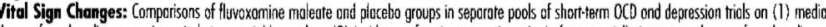
change from baseline on vorious vitol signs variobles and on (2) incidence of patients meeting criterio for potentiolly important changes from boseline on vorious vital signs variobles revecled no important differences berween fluvoxamine malente and placebo.

Loboratory Changes: Comporisons of fluvoxamine molecte ond plocebo groups in sepcrate pools of short-term OCD and depression tricls on (1) medion change from boseline on various serum chemistry, hemnotology, ond uinolysis variobles ond on (2) incidence of potients meeting criterio for potentially important chonges from
moleate and plocebo.

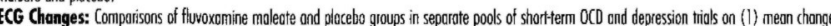
from boseline on various $\mathrm{ECG}$ variobles ond on (2) incidence of patients meeting criterio for potentially importont chonges from boseline on various $\mathrm{ECC}$ voriobles ievecled no important differenceses between fuvoxamine moleote ond plocebo.

Other Events Observed During the Premarketing Evaluation of LUVOX Tablets: Duing premerketing clinical riols conducted in North America and Europe, mutiple doses of fluvoxonnine moleate were administered for o combined total of 2737 potient exposutes in patients suffering OCD or Mojor Depressive Disorder. Untoward events ossociated with this exposure were recorded by clinical investigctors using descriptive terminology of their own choosing. Consequently, it is not possible to provide o meaningful essimote of the proportion of individuals experiencing adverse events without first grouping similar types of untoward events into o linited (i.e., reduced) number of stondord event cotegocies. In the tobulations which follow, a stondar

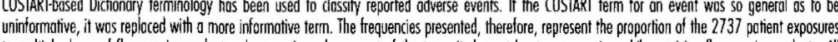
to mulfiple coses of fluvoxamine moleate who experienced on event of the type cited on at leass one occasion while receiving fluvoxomine moleote. All to mulfiple coses of fluvoxamine moleate who expeienced on event of the type cited on at least one occasion while receiving fllovoxomine moleote. An

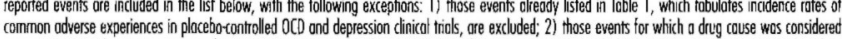

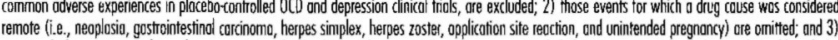
remote (i.e., neoplosia, gostrinintestinol corcinomo, herpes simplex, herpes zoster, opplicotion site reaction, and unintended pregnancy) ore omitted; and 3)
events which were reported in only one potient ond judged to not be potentiolly serious ore not included. It is importent to emphosize that, attiough the

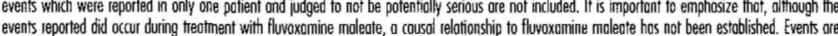
further clossitied within body system contegories ond enumerofed in order of decreasing frequency using the following definitions: frequent odverse events ore defined as those occurring on one or ore defined as those occurring on one or more occasions in at least $1 / 100$ potients; infrequent odverse everts are those occurring between $1 / 100$ ond 1/1000 potients; and rare adverse events are those occuring in less thon I/1000 potients. Body as a Whole: Frequent: occidentol iniury, moloise; Infrequent: allergic reaction, neck pain, neck rigidity, overdose, photosensifivity reoction, suicide othempt, Rore: cyst, pelvic pain, sudden death.

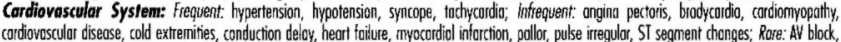

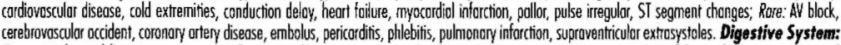

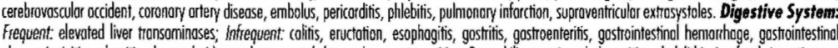

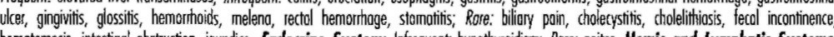
hemotemesis, intestinal obstruction, joundice. Endocrine System: infrequent: hypothyroidisn;; Rore: goiter. Hemic and Lymphotic Systems: infrequent: anemio, ecchymosis, leukocytosis, lymphadenopostly, thrombocytopenia; Rare: leukopenia, purpurc. Metabolic and Nutritional Systems: frequent: ederno, weight gain, weight loss; intrequent: dehydrotion, hypercholessterolemia; Rore: dicbetes mallins, hyperghyeenio, hyperipidemio, hypoglycernio, hypokolemio, lactate dehydrogenase increosed. Musculosheletal System: infrequent: arthrolgia, arthritis, bursitis, generalized muscle

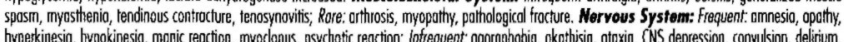

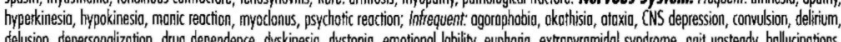
detusion, depersonaizotion, drug dependence, dyskinesia, dystonic, emotionol lability, euphoria, extropyramidal syndrome, goit unsteody, hollucinations,

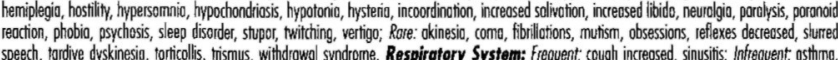
bronchitis, epistaxis, hoorseness, hyperventiletion, Rare: apnea, congestion of upper dirway, hemophysis, hiccups, leryngismus, obstructive puimonory

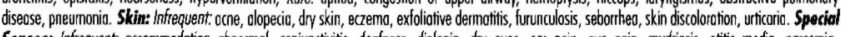

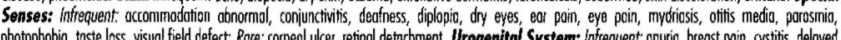

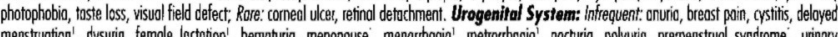

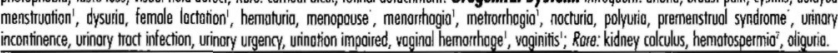
incontinence, uninory troct infection, urinory urgency, uninotion impoi

Non-US Postmarketing Reports: Voluntary reparts of acverse events in patients toking LUVOX" Toblets thot hove been received since maike introduction and are of unknown cousol relotionship to LUVOX Toblets use incude: toxic epidermol necrolysis, Stevenss-ohnson syndrome, Henoch

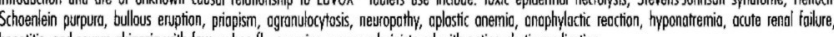
hepcititis, and severe ckinesio vith tever when fluvoxornine wos co-sdministered with ontipsychotic medicotion.

\section{OVERDOSAGE}

Refer to pockoge insert (15E Rev $5 / 99)$ for overcosogoge information

DOSAGE AND ADMINISTRATION

R. only

\section{Solvay Pharmaceuticals}

Rev 6/99 (1280/1285 15E Rev 5/99

Solvay

Pharmaceuticals

(C) 2000 Solvay Pharmaceuticals, lnc. All rights reserved. INX00025 Junu:iry 2000 


\section{"My doctor diagnosed obsessions and compulsions and prescribed LUVOX Tablets."}

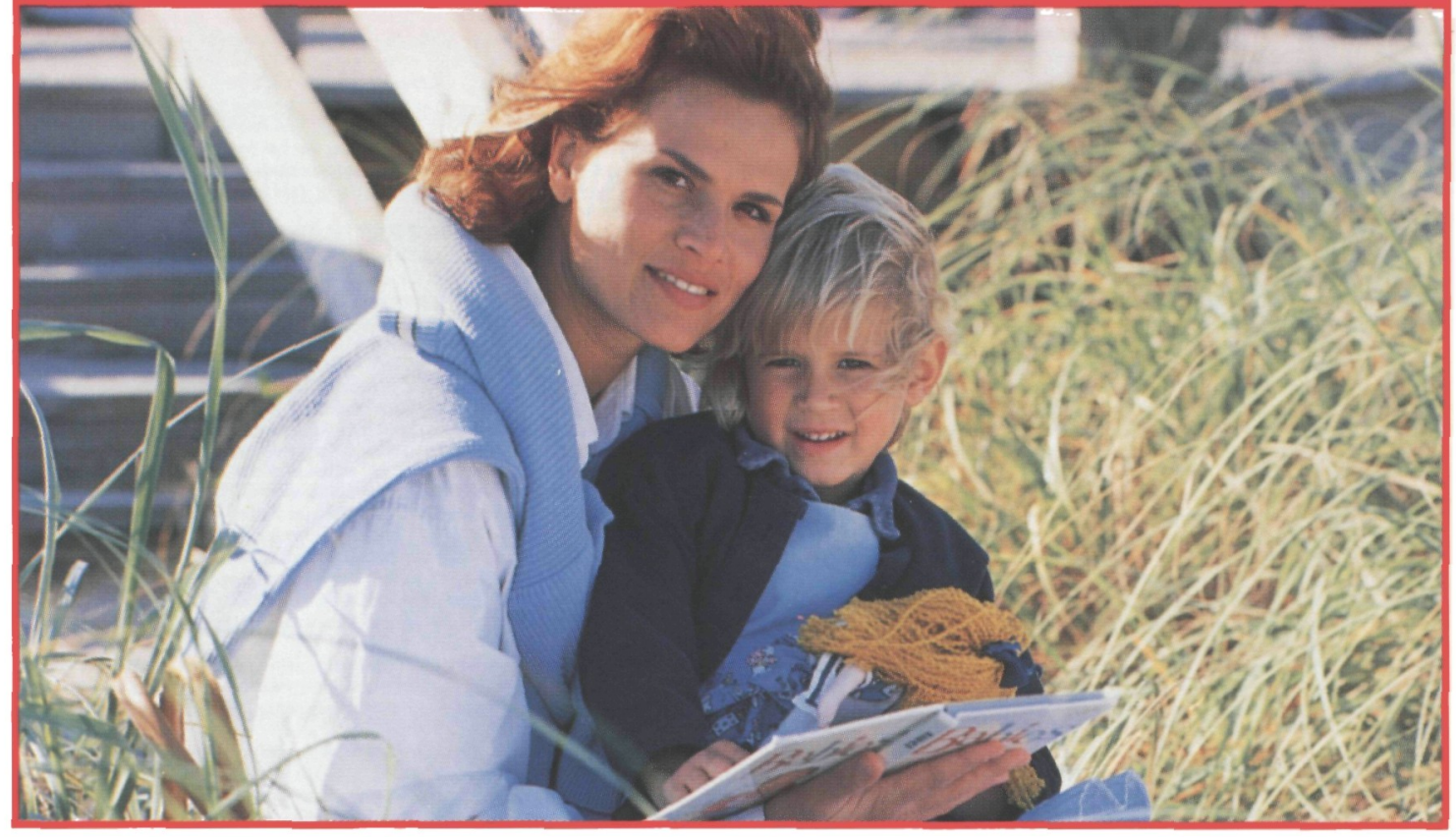

- IMPROVES OBSESSIVE-COMPULSIVE SYMPTOMS IN ADULTS, CHILDREN, AND ADOLESCENTS ${ }^{2,3}$

จ LOW INCIDENCE OF SEXUAL DYSFUNCTION IN ADULTS ${ }^{4}$

LUVOX Tablets vs placebo: decreased libido $2 \%$ vs $1 \%$; delayed ejaculation $8 \%$ vs $1 \%$; impotence $2 \%$ vs $1 \%$

$\checkmark$ LOW INCIDENCE OF AGITATION IN ADULTS ${ }^{4}$

$2 \%$ vs $1 \%$ for placebo

In adults, the most commonly observed adverse events compared to placebo were somnolence $22 \%$ vs $8 \%$; insomnia $21 \%$ vs $10 \%$; nervousness $12 \%$ vs $5 \%$; nausea $40 \%$ vs $14 \%$; asthenia $14 \%$ vs $6 \%{ }^{4}$

In children and adolescents, the most commonly observed adverse events compared to placebo were: agitation $12 \%$ vs $3 \%$; hyperkinesia $12 \%$ vs $3 \%$; depression $5 \%$ vs $0 \%$; dysmenorrhea $7 \%$ vs $3 \%$; flatulence $5 \%$ vs $0 \%$; rash $7 \%$ vs $3 \%^{4}$

Concomitant use of LUVOX ${ }^{\circledR}$ Tablets and monoamine oxidase inhibitors is not recommended. ${ }^{4}$

Fluvoxamine should not be used in combination with terfenadine, astemizole, cisapride, or pimozide. ${ }^{4}$

As any psychoactive drug may impair judgment, thinking, or motor skills, patients on LUVOX ${ }^{\circledast}$ Tablets should be advised to exercise caution until they have adapted to therapy.

References: 1. Physician Drug \& Diagnosis Audit (PDDA) and Source ${ }^{\text {TM }}$

Prescription Audit (SPA) August 1998-September 1999. Scott-Levin, a

division of Scott-Levin PMSI Inc. 2. Goodman WK, Kozak MJ, Liebowitz M,

et al. Treatment of obsessive-compulsive disorder with fluvoxamine: a multi-

centre, double-blind, placebo-controlled trial. Int Clin Psychopharmacol.

1996;11:21-29. 3. Data on file, Study in Children and Adolescents

(Report No. CR200.0116), Solvay Pharmaceuticals. 4. LuVOX Tablets Full Prescribing Information.

\section{VISIT OUR OCD WEB SITE AT www.ocdresource.com}

\section{Solvay}

\section{Pharmaceuticals}

Please see brief summary of prescribing information on adjacent page.

(C)2000 Solvay Pharmaceuticals, Inc. All rights reserved.

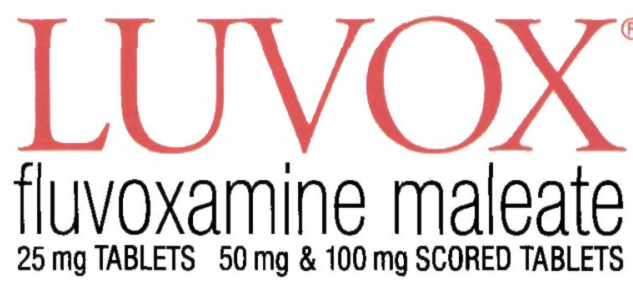

First-line SSRI therapy for obsessions and compulsions 